\title{
THE EFFECT OF TOTAL PERIPHERAL RESISTANCE ON INDICATOR-DILUTION CURVES FROM THE GENTRAL CIRCULATION OF THE DOG
}

\author{
Guy C. Davis, JR., A. Wulliam Paulsen, and Evan L. Frederickson
}

\section{INTRODUCTION}

CARDIAC OUTPUT is measured in the operating room and in intensive care units with increasing frequency. A common method of measurement is the indicatordilution technique in which a bolus of indocyanine green dye is injected into the central venous system and its concentration as a function of time is measured in a peripheral systemic artery. The cardiac output determination is based solely upon the area under the primary indicator-dilution curve and is not influenced by the shape of the curve. ${ }^{1}$

In measuring cardiac output both clinically and in the laboratory we noted that the shape of the curve varied widely and did not necessarily correspond to the cardiac output. In fact, the shape of the curve might be quite different for two similar cardiac outputs. The shape of the dye curve is determined by the dispersion of the indicator particles during transit through the central circulation. This dispersion results from two main processes: (1) dispersion which occurs within a single vessel or cardiac chamber due to the nonuniform velocity profile, and (2) dispersion which occurs due to various fractions of the indicator passing through different physical pathways with different lengths. The observed indicatordilution curve is the transfer function of the pulmonary circulation plus the right and left heart. ${ }^{2,3}$

The standard deviation of the primary indicator-dilution curve is a measure of the dispersion of indicator particles occurring between the injection and the sampling sites. Bassingthwaighte and co-workers determined the transfer functions for a segment of the artery of the human $\operatorname{leg}^{4, \overline{5}}$ and the aorta of the dog. ${ }^{3}$ They found that the dispersion was greatest in the central circulation, less in the aorta, and still less in the arteries of the leg. ${ }^{4}$ The relative dispersion occurring in a single vessel remained unaffected by variations in flow rate over a wide range. Another study of transpulmonary circulatory transport functions showed that the relative dispersion tended to increase as the mean transit time increased. ${ }^{6}$

The purpose of this investigation was to determine the relationship of the total

Guy C. Davis, Jr., M.D., Ph.D., Research Fellow, Anesthesiology, Clinical Associate, Statistics and Biometry. (Present address: Department of Anesthesiology, Duke University, Durham, North Carolina 27710)

A. William Paulsen, M.M.Sc., Instructor, Division of Allied Health Sciences.

Evan L. Frederickson, M.D., Professor, Anesthesiology.

Department of Anesthesiology and the Department of Statistics and Biometry, Emory University, Atlanta, Georgia 30322.

This investigation was supported in part by N.I.H. Grant GM 01508. 
peripheral resistance to the dispersion of indicator particles passing through the central circulation over a wide range of cardiac outputs.

\section{Materials and Methods}

Multiple indocyanine green indicator-dilution curves were obtained from five anaesthetized mongrel dogs ranging in weight from 18 to $24 \mathrm{~kg}$. The unpremedicated animals were anaesthetized with sodium thiopentone $25 \mathrm{mg} / \mathrm{kg}$ intravenously; sodium pentobarbitone $5 \mathrm{mg} / \mathrm{kg} / \mathrm{hr}$ was administered for maintenance of anaesthesia. Ventilation was controlled by a volume ventilator with the dog receiving an inspired oxygen concentration of 100 per cent. Central venous pressure was measured from a catheter inserted into the right femoral vein and advanced until the tip was positioned at the junction of the cavae and the right atrium. This catheter was also used for injection of the indocyanine green dye, while another catheter was inserted into the opposite femoral artery and positioned in the ascending aorta for measurement of mean systemic arterial pressure. The intravenous administration of sodium nitroprusside and methoxamine altered the peripheral vascular resistance of the dog.

The pressure signals were obtained from Statham P23Db strain gauge transducers and conditioned by the Electronics for Medicine model SGM-2 pressure amplifiers. These signals were displayed on the Electronics for Medicine DR-8 Simultrace Recorder and recorded on magnetic tape using an Ampex SP-300 tape recorder.

Arterial blood gases were drawn to assess the adequacy of ventilation and to monitor acid-base balance. The oesophageal temperature did not vary more than $0.5^{\circ} \mathrm{C}$ during the course of any one experiment.

We obtained dye curves by rapidly injecting a $1.0 \mathrm{ml}$ bolus of $2.5 \mathrm{mg}$ of indocyanine green dye through the central venous pressure line into the central circulation. Blood was withdrawn by a Harvard pump from the aortic catheter through the densitometer head into a heparinized $50 \mathrm{ml}$ syringe at a constant rate of $38 \mathrm{ml} / \mathrm{min}$, then reinfused into the dog after each curve. The output from the densitometer was recorded on the servo channel (Gilson IC-S3) of a five-channel Gilson Polygraph and also on magnetic tape. Data analysis was done later using the analog signals recorded on magnetic tape. Each dye curve was digitized with a Hewlett-Packard 5451A Fourier Analyzer at the rate of 256 points per 50 seconds, then processed on a Unvivac 70/7 digital computer by fitting the first portion of each curve to the random walk function. ${ }^{7,8}$ The curves were fitted to the functions using nonlinear regression analysis techniques which provided least squares estimates of the function for each curve. ${ }^{9}$ The random walk function

$$
h(t)=\left[\frac{\mu}{\pi \mathrm{Kt}^{3}}\right]^{\frac{1}{2}} \exp \left[-\frac{(\mu-\mathrm{t})^{2}}{\mu \mathrm{Kt}}\right], \quad 0 \geq \mathrm{t} \geq \infty
$$

is a probability density function with parameters $\mu$ and $\mathrm{K}$. The mean and standard deviation of $h(t)$ are $\mu$ and $\sigma=\left(1 / 2 \mu^{2} \mathrm{~K}\right)^{1 / 2}$, respectively. To fit the function to the 


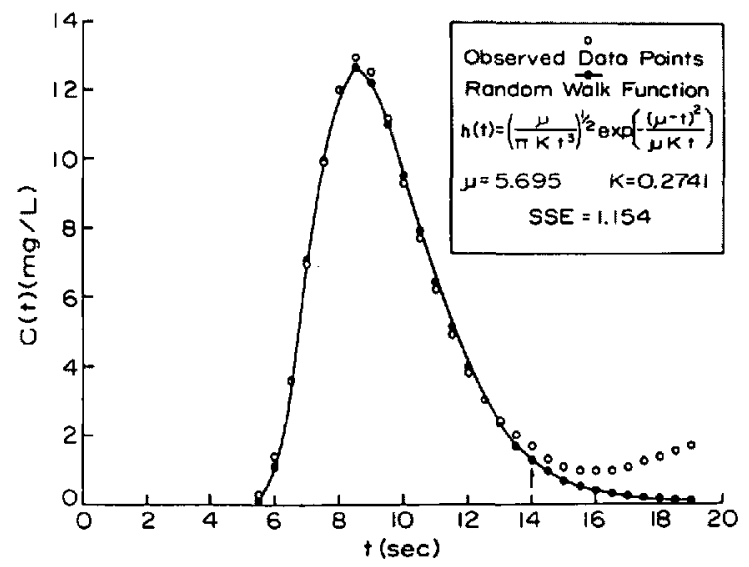

Figure 1. Random walk function fitted to a pulmonary indicator-dilution curve. The arrow indicates the point where the data were truncated to avoid the effects of recirculation of indicator in the nonlinear regression program used to fit the model to the data. The SSE (sum of squares of errors) is the sum of the squares of the difference between the observed data points and the estimated values.

data, an alternate form of the equation with two additional parameters must be used:

$$
\mathrm{h}(\mathrm{t})=\mathrm{A}\left[\frac{\mu}{\pi \mathrm{K}\left(\mathrm{t}-\mathrm{t}_{0}\right)^{3}}\right]^{\frac{1}{2}} \exp \left[-\frac{\mu-\left(\mathrm{t}-\mathrm{t}_{0}\right)^{2}}{\mu \mathrm{K}\left(\mathrm{t}-\mathrm{t}_{0}\right)}\right]
$$

The parameter $A$ is the area under the curve, and $t_{0}$ is a parameter that shifts the origin of the curve to obtain the best fit. The parameter $\mu$ is the mean of the function with the origin at the appearance time and not the mean transit time measured from the time of injection.

Figure 1 shows a typical recorded dye curve and the least squares estimate of the random walk function obtained from non-linear regression analysis. The arrow indicates the point where the data were truncated for the regression analysis to avoid the effects of recirculation. The regression curve approximates the primary indicator curve without recirculation.

\section{Results}

The cardiac output, mean arterial-venous pressure difference, total peripheral resistance and the standard deviation of the primary indicator-dilution curve are given for each of the five dogs in Table I. The observations for each animal are arranged in order of increasing total peripheral resistance. There is a linear trend when either the total peripheral resistance, the mean arterial-venous pressure difference or the cardiac output was regressed against the standard deviation. The slope of the regression line was positive with pressure and resistance, and negative with cardiac output. As can be seen in Table II, there was much less scatter in the data, as measured by the correlation coefficient, in the case of the total peripheral resistance than in the case of either the pressure difference or the cardiac output. 
TABLE I

SumMary OF Results

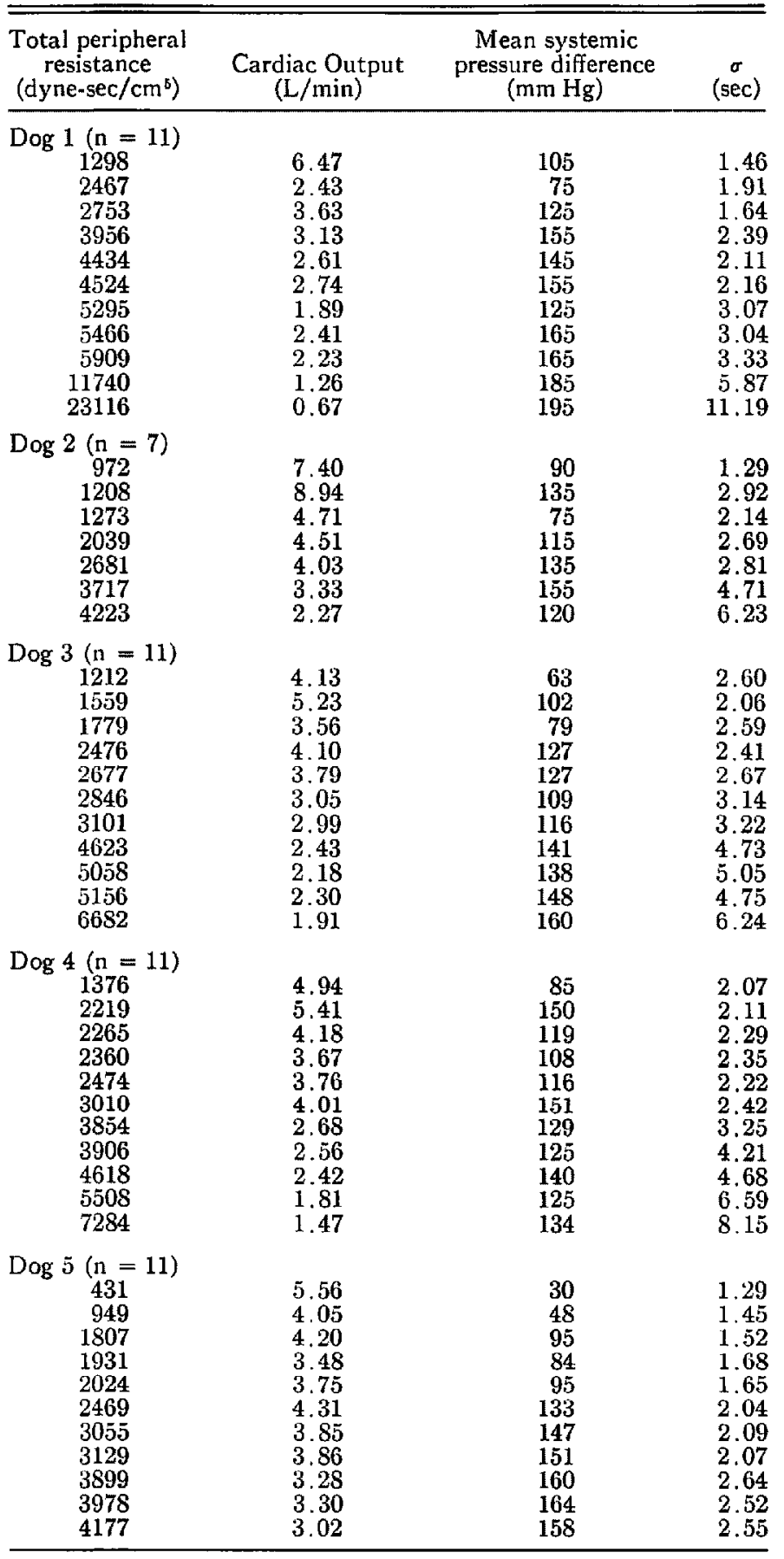


TABLE II

\begin{tabular}{|c|c|c|c|}
\hline \multirow[b]{2}{*}{ Dog } & \multicolumn{3}{|c|}{ Correlation coefficient } \\
\hline & $\begin{array}{c}\text { Cardiac } \\
\text { output }\end{array}$ & $\begin{array}{l}\text { Pressure } \\
\text { difference }\end{array}$ & $\begin{array}{l}\text { Total } \\
\text { peripheral } \\
\text { resistance }\end{array}$ \\
\hline 1 & 0.655 & 0.682 & 0.992 \\
\hline 2 & 0.665 & 0.545 & 0.851 \\
\hline 3 & 0.908 & 0.758 & 0.945 \\
\hline 4 & 0.873 & 0.226 & 0.944 \\
\hline 5 & 0.741 & 0.928 & 0.945 \\
\hline
\end{tabular}

The linear regression of the standard deviation of the fitted random walk function on the total peripheral resistance is given for each of the five dogs in Figure 2.1-2.5. The regression equation, correlation coefficient, and $\mathrm{p}$ value are also given for each animal. The correlation coefficients of the regression equations range from 0.85 to 0.99 , indicating a good fit of the data. The addition of either cardiac output or mean arterial pressure to the regression equation in a multiple stepwise linear regression did not significantly improve the fit at the 5 per cent probability level.

\section{Discussion}

Our study shows that the standard deviation of primary indicator-dilution curves from the central circulation is linearly related to the total peripheral resistance. This implies that changes in the total peripheral resistance are consistently correlated with changes in the dispersion characteristics of the central circulation. There are two possible mechanisms for this relationship; either (1) the changes in the periphery are directly influencing the pulmonary circulation, or (2) the pharmacological agents that are controlling the peripheral resistance are also influencing the pulmonary circulation. Further investigation will be necessary to determine the correct mechanism.

The slopes of the regression lines varied from animal to animal, in our study, suggesting that the cardiovascular systems of the animals were different. This could be due to various factors including age of the animal and altered vascular compliance. Since the dispersion is greatest in the pulmonary circulation, these results indicate that the response of the pulmonary circulation to changes in total peripheral resistance is consistently linear for any given dog but that the magnitude of the response varies from animal to animal. The dispersion of an indicator for a given cardiac output will be greater when the total peripheral resistance is high and less when the resistance is low. By definition, the area of an indicator-dilution curve is directly related to cardiac output; however, the shape of the curve and 

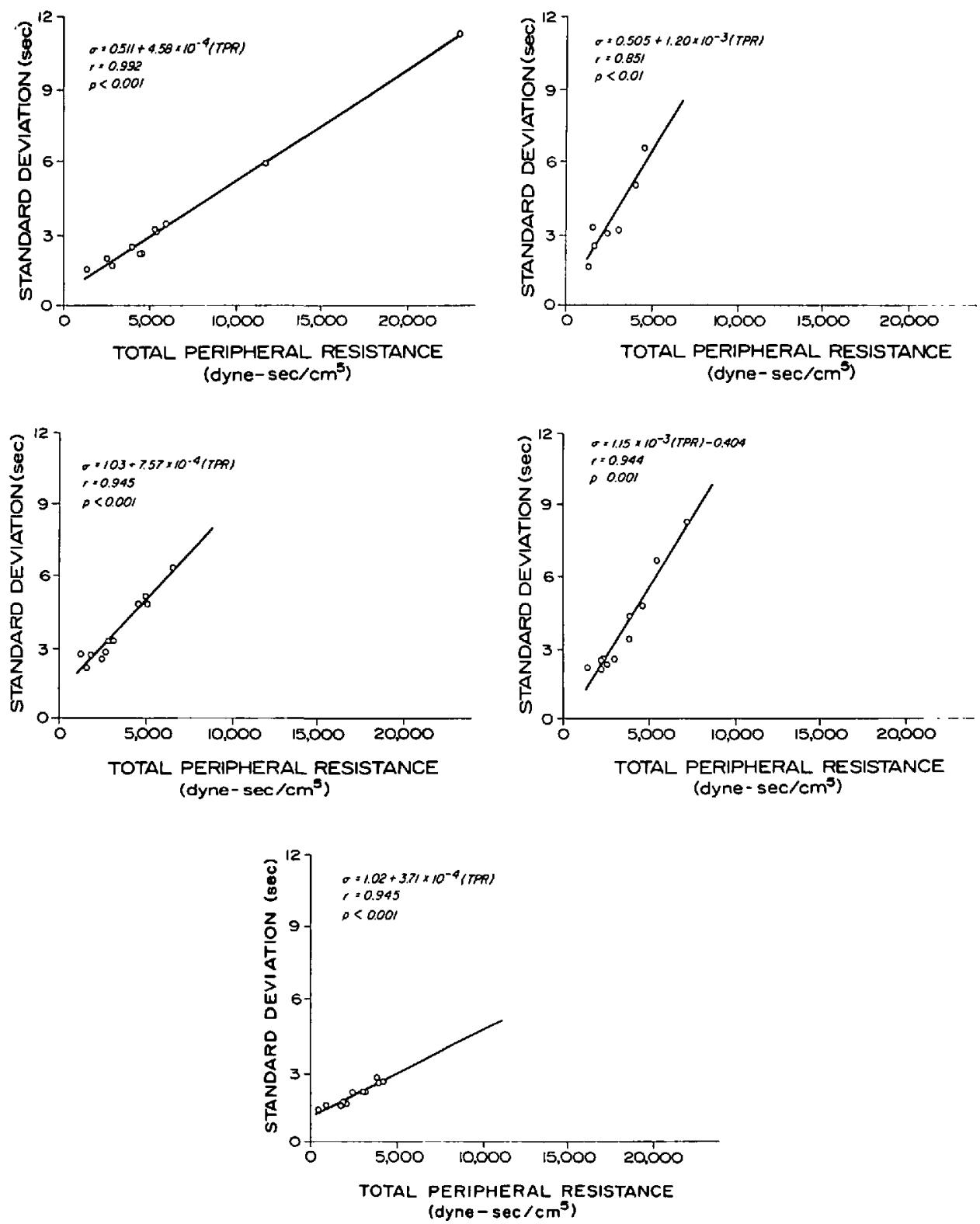

Ficune 2.1-2.5 The linear regression of the standard deviation of transpulmonary indicatordilution curves on the total peripheral resistance for each of the five dogs.

in particular the standard deviation is shown to be related to the total peripheral resistance.

Other investigators, ${ }^{10,11}$ have found that the shape of an indicator-dilution curve provides information about the adequacy of myocardial function and cardiac reserve. Our results show that an indicator-dilution curve provides information about the peripheral circulation as well as the cardiac output. 


\section{SUMMARY}

The influence of total peripheral resistance on the dispersion of indicator particles passing through the central circulation was studied in five dogs. The standard deviation of indocyanine green indicator-dilution curves provided a measure of dispersion. The peripheral vascular resistance of the dog was altered during the experiment by the intravenous administration of sodium nitroprusside and methoxamine. We calculated the area of each curve by fitting the first portion of the curve to a random walk function and the cardiac output and the total peripheral resistance were calculated in the usual manner. The mean, standard deviation and area of each of the curves were calculated from the least squares estimate of the random walk function. The relationship of the cardiac output, mean arterial pressure, and total peripheral resistance to the mean and the standard deviation were compared in a multiple stepwise linear regression. For each dog there was a definite linear relationship between total peripheral resistance and standard deviation $(p<0.01$ ). These results indicate that the dispersion of particles passing through the central circulation is directly related to the total peripheral resistance.

\section{REFERENCES}

1. Zierler, K.L. Circulation times and the theory of indicator-dilution methods for determining blood flow and volume. Handbook of Physiology, Section 2: Circulation, Volume 1, edited by W.F. Hamilton, P. Dow. Washington, American Physiological Socicty, pp. 585-615 (1962).

2. Meier, P. \& ZienLer, K.L. On the theory of the indicator-dilution method for measurement of blood flow and volume. J. Appl. Physiol. 6: 731 (1954).

3. Bassingthwaighte, J.B. \& ACKerman, F.H. Mathematical linearity of circulatory transport. J. Appl. Physiol. 22: 879 (1967).

4. Bassingthwaighte, J.B., Ackerman, F.H., Wood, E.H. Applications of the lagged nommal density curve as a model for arterial dilution curves. Circ. Res. 18: 398 (1966).

5. Bassingthwaichte, J.B. Plasma indicator dispersion in arteries of the human leg. Circ. Res. 19: 332 (1966).

6. KNOPP, T.J. \& Bassincthwaighte, J.B. Effect of flow on transpulmonary circulatory transport functions. J. Appl. Physiol. 27: 36 (1969).

7. Sheppand, C.W. Mathematical considerations of indicator dilution techniques. Minn. Med. $37: 93$ (1954).

8. Sheppard, C.W. \& UFFER, M.B. Stochastic models for tracer experiments in the circulation. II. Serial random walks. J. Theoret. Bio. 22: 188 (1969).

9. Draper, N.R. \& Smith, H. Applied regression analysis, lst ed., New York: John Wiley \& Sons, Inc., pp. 263-304 (1966).

10. Gudwin, A.L., Goldstein, C.R., Cohn, J.D., \& DelGuercio, L.R.M. Estimation of ventricular mixing volume for prediction of operative mortality in the elderly. Ann. Surg. 168: 183 (1968).

11. Siecel, J.H., Farrelt, E.J., \& Lewin, I. Quantifying the need for cardiac support in human shock by a functional model of cardiopulmonary vascular dynamics with special reference to myocardial infarction. J. Surg. Res. 13: 166 (1972). 